\title{
ALTERAÇÕES BIOQUÍMICAS DURANTE A EMBEBIÇÃO DE SEMENTES DE CATINGUEIRA (Caesalpinia pyramidalis Tul.) ${ }^{1}$
}

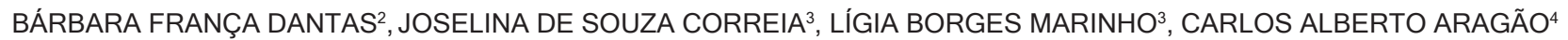

\begin{abstract}
RESUMO - A Caesalpinia pyramidalis Tul. é ima espécie nativa da catinga resistente à seca e de grande potencial econômico. A germinação das suas sementes compreende uma série de processos, que começa com a embebição de água e termina com a emergência da plântula através do tegumento. Iniciada a germinação das sementes, ocorre a ativação de enzimas hidrolíticas pré-existentes e a síntese denovo.de outras enzimas hidrolíticas que induzem a mobilização das reservas. Pouco se conhece sobre a velocidade de embebição e metabolismo germinativo desta espécie, portanto o objetivo deste trabalho foi obter a curva de embebição e avaliar as alterações bioquímicas que ocorrem nas sementes de catingueira durante a germinação. As sementes foram separadas em três repetições de 20 sementes para cada tempo de embebição, que foi de uma, duas e três horas e, posteriormente a cada três horas até $72 \mathrm{~h}$. As sementes foram colocadas em "gerbox", sobre duas camadas de papel embebido em $15 \mathrm{~mL}$ de $\mathrm{H}_{2} \mathrm{Od}$. Antes e após o tempo de embebição, as sementes foram pesadas. Em seguida, o material foi congelado para análise de açúcares solúveis totais (AST), açucares redutores (AR), amido, proteínas totais (PT), e as proteínas de reserva: globulinas, prolaminas, albuminas e glutelinas. A curva de embebição das sementes de catingueira apresentou modelo trifásico, onde a fase (F) I foi completada em 24h e a FIII iniciou-se após 54h de embebição. Os teores de AR nas sementes aumentam durante a embebição, enquanto os teores de AST diminuem e de amido permanecem constante. As proteínas de reserva, os teores de albuminas, globulinas e prolaminas aumentam durante a embebição. Por outro lado os teores de glutelinas diminuem na FI e permanecem constantes durante FII e FIII.
\end{abstract}

Termos para indexação: metabolismo, germinação, mobilização de reservas, caatinga.

BIOCHEMICAL CHANGES DURUING IMBIBITION OF Caesalpinia pyramidalis Tul. SEEDS

ABSTRACT - Caesalpinia pyramidalis Tul. is a native species for caatinga biome, with a great resistance to drought and with great economic potential. The seeds germination comprehends cascade processes that start with the water imbibition and ends with the seedling emergence through the seed tegument. Once it starts, the activation of pre-existing hydrolytic enzymes and the denovo synthesis if other hydrolytic enzymes, leading to reserves mobilization. Little is known about the imbibition rate and germinative metabolism of $C$. pyramidalis, therefore the objective of this wok was to obtain the imbibition curve and evaluate biochemical changes that take place during germination of $C$. pyramidalis. Three replication of twenty seeds were subjected to each imbibition period, which were

${ }^{1}$ Submetido em 26/02/2007. Aceito para publicação em 08/12/2007.

${ }^{2}$ Pesquisadora, Embrapa Semi-Árido. Laboratório de Sementes e Fisiologia Vegetal, Embrapa Semi-Árido, CP23, CEP56302-970, Petrolina-PE. Email: barbara@cpatsa.embrapa.br
${ }^{3}$ Engenheira Agrônoma, DTCS, UNEB, Campus III, Juazeiro - BA.

${ }^{4}$ Professor Adjunto, DTCS, UNEB, Campus III, Juazeiro - BA. Email: carlosaragao@hotmail.com 


\begin{abstract}
1, 2, 3 hours $(\mathrm{H})$ and after that at intervals of $3 \mathrm{~h}$ until $72 \mathrm{~h}$. The seeds were placed in gerbox over two layers of germination paper moisten in $15 \mathrm{~mL}$ of distilled water. Before and after each imbibition period the seeds were weighted and frozen until extraction and analysis of the contents of total soluble sugars (AST), reducing sugars (AR), starch and reserve proteinas (albumine, globuline, prolamine and gluteline). The imbibition curve fo C. pyramidalis seeds presented triphasic model, in wich phase (F) I was completed after $24 \mathrm{~h}$ and FIII initiated after $51 \mathrm{~h}$ imbibition, following root protrusion at $54 \mathrm{~h}$. The AR content increases during imbibition, while AST decreases and starch stays relatively constant during imbibition. Regarding the reserve proteins, albumine, globuline and prolamine increased during imbibition and, inversely, gluteline decreased during FI and remains constant during FII and FIII.
\end{abstract}

Index terms: metabolism, germination, reserve mobilization, Caatinga.

\section{INTRODUÇÃO}

O Brasil possui 385 milhões de hectares de florestas nativas (IPEF, 2000), sendo que a região de Caatinga tem cerca de 800 mil km², totalizando $11 \%$ do território nacional e $70 \%$ do território nordestino, abrangendo os estados do Ceará, Rio Grande do Norte, Paraíba, Pernambuco, Sergipe, Alagoas, Bahia, sul e leste do Piaú e norte de Minas Gerais (Lima, 1996).

A Caatinga tem uma fisionomia de deserto, com índices pluviométricos muito baixos, em torno de 500 a $700 \mathrm{~mm}$ anuais. A temperatura se situa entre 24 e $26^{\circ} \mathrm{C}$ e varia pouco durante o ano. Além dessas condições climáticas rigorosas, a região das caatingas está submetida a ventos fortes e secos, que contribuem para a aridez da paisagem nos meses de seca (Sampaio e Rodal, 2000).

Dentre as espécies nativas da Caatinga, a catingueiraverdadeira (Caesalpinia pyramidalis Tul.) apresenta grande potencial econômico devido à sua rusticidade e ao seu aproveitamento madeireiro, ao potencial para reflorestamento, ao uso medicinal e principalmente à sua propriedade extrativa (Oliveira, 1976). A catingueira-verdadeira, que possui potencial forrageiro, madeireiro emedicinal, com propriedades antidiarréicas. Após o início das chuvas, em alguns dias a folhagem desta espécie libera um cheiro pungente, sendo desprezadas pelo rebanho. As folhas, então, secam e caem no início da estação seca, tornando-se uma forragem nutritiva neste período (Pfeister e Malechek, 1986). Essa característica garante a disponibilidade de forragem de catingueira durante o período seco (Hardesty et al., 1988). Segundo, Nishizawa et al. (2005) essa espécie produz madeira para lenha, carvão e estacas, com densidade de $0,85 \mathrm{~g} \cdot \mathrm{m}^{-3}$. As folhas, flores e casca são, também, usadas no tratamento das infeções catarrais e nas diarréias e disenterias (Nishizawa et al., 2005) além disto, as folhas de $C$. pyramidalis Tul., são empregada para febre, doenças estomacais e como diurético (Bahia, 1979).

Oconhecimentodecomoosfatoresambientaisinfluenciam a germinação das sementes é de extrema importância. Assim, eles poderão ser controlados e manipulados de forma a aperfeiçoar a porcentagem, velocidade e uniformidade de germinação, resultando na produção de mudas mais vigorosas para plantio e minimização dos gastos (Nassif et al., 1998)

De uma maneira geral, durante a formação da semente, observa-se inicialmente, um acúmulo de açúcares tais como sacarose, frutose e glicose, bem como, compostos nitrogenados como aminoácidos e amidas. Estas substâncias drenadas da planta mãe são os principais metabólitos para a formação dos tecidos da semente e das substancias de reserva que serão acumulados para fornecimento de energia e substâncias básicas para o desenvolvimento do processo de germinação. Desta forma, à medida que a semente vai se desenvolvendo há uma diminuição na quantidade destas substâncias mais simples e, ao mesmo tempo, um acumulo de moléculas maiores e mais complexas como as proteínas, amido, lipídios, celulose, etc. (Guimarães, 1999).

A absorção de água pelas sementes é o primeiro passo da germinação, sem o qual este processo não pode ocorrer. A reativação do metabolismo conhecida por fase Iécaracterizada pelo rápido aumento da respiração, proporcional ao aumento da hidratação dos tecidos das sementes. $\mathrm{Na}$ indução do crescimento, fase II, a atividade respiratória se estabiliza. A terceira fase, na qual a absorção da água tende a aumentar ocorre um segundo aumento na atividade respiratória, que se associa a maior disponibilidade de oxigênio, como conseqüência da ruptura da testa produzida pela emergência da radícula e o crescimento da plântula (Guimarães, 1999).

Iniciada a germinação das sementes ocorre à ativação da síntese protéica, a formação de enzimas hidrolíticas que produzem a mobilização das reservas.

Desta forma, este trabalho teve como objetivo obter a curva de embebição das sementes de catingueira (Caesalpinia pyramidalis Tul.), assim como avaliar as alterações bioquímicas das sementes que ocorrem durante processo de germinação. 


\section{MATERIAL E MÉTODOS}

O experimento foi conduzido no Laboratório de Sementes e Fisiologia Vegetal na Embrapa Semi-Árido, em Petrolina-PE. As sementes de catingueira (Caesalpinia pyramidalis Tull.) foram separadas em três repetições de 20 sementes, para cada tempo de embebição, sendo eles, 1, 2 e 3 horas e, posteriormente a cada 3 horas até 72 horas. As sementes foram colocadas em gerbox sobre duas camadas de papel germitest, embebido com $15 \mathrm{~mL}$ de água destilada. Antes e após os tempos de embebição, as sementes foram pesadas, Após a segunda pesagem as sementes foram congeladas a $-20^{\circ} \mathrm{C}$, até extração de açúcares e proteínas reserva.

Para extração dos açúcares solúveis e insolúveis, as sementes foram maceradas em água destilada na proporção de 10:1 (p:v) e a solução foi centrifugada a $4500 x g$ por 15 minutos. O sobrenadante foi armazenado em freezer $-20^{\circ} \mathrm{C}$ até análises de açúcares redutores (AR) e açúcares solúveis totais (AST). O precipitado, material insolúvel em água, foi utilizado para extração perclórica de amido (Allen, 1977). Os teores de AR nas sementes foram quantificados utilizando o reagente DNS (ácido dinitrosalicílico), baseado em curva de referência de glicose (Miller, 1959) e os teores de AST e amido foram quantificados de acordo com Morris (1948) e Yemm e Willis (1954), utilizando-se o reagente antrona e curva de referência a partir de concentrações conhecidas de glicose.

Para a extração seqüencial das proteínas de reserva, as sementes foram maceradas em $10 \mathrm{~mL}$ do primeiro extrator $\left(\mathrm{H}_{2} \mathrm{O}\right.$ destilada). Após incubação a $25^{\circ} \mathrm{C}$, durante 30 minutos, as amostras foram centrifugadas a $3000 \mathrm{xg}$ durante 20 minutos. O sobrenadante foi, então, coletado e o precipitado ressuspendido com o mesmo volume inicial do mesmo extrator, repetindo por mais duas vezes a incubação, centrifugação e coleta do sobrenadante. Após as três coletas de $10 \mathrm{~mL}$ obteve-se a fração de albuminas. O resíduo da extração da fração albumina foi submetido à extração da fração globulina de forma semelhante utilizando, como extrator, $\mathrm{NaCl}(1 \%)$. O mesmo ocorreu para as extrações de prolamina e glutelina, utilizando os extratores etanol (70\%) e $\mathrm{NaOH}\left(0,1 \mathrm{~mol} \mathrm{~L}^{-1}\right)$, respectivamente (Aragão et al., 2003). A quantificação das proteínas foi feita pelo método de Bradford (1976), utilizando o reagente Comassie Blue G-250. As leituras foram feitas em espectrofotômetro a $595 \mathrm{~nm}$ e comparadas com a curva de referência obtida com concentrações conhecidas de soro-albumina bovina - BSA.

\section{RESULTADOS E DISCUSSÃO}

As sementes de caatingueira apresentaram uma média de $9,46 \%$ de teor de água antes de serem submetidas à embebição. A germinação das sementes de catingueira $(C$. pyramidalis) se ajustou ao modelo trifásico, onde a fase I (FI) foi completada em 24 horas e a fase III (FIII) iniciou-se após 51 horas de embebição. Às 54 horas de embebição foram verificados $10 \%$ de plântulas com protrusão da raiz e um aumento de, aproximadamente $76 \%$ do peso inicial (Figura 1). Seiffert (2002) verificou que sementes de Protium widgrenii necessitam de 72 horas para que o processo de germinação fosse completado e ocorresse a protrusão da raiz. Segundo essa autora, a FI foi relativamente longa, necessitando de 30 horas para ser completada apresentando apenas $4 \%$ de ganho de peso. Essas sementes, no entanto, apresentaram aproximadamente $50 \%$ de teor de água inicial. Almeida (2002) verificou que sementes de Cryptocaria aschersoniana Mez., da mesma forma que as sementes estudadas neste trabalho, apresentaram rápido ganho de peso. Sementes de Simarouba amara (Simaroubacea) apresentaram, semelhantemente às sementes do presente estudo, aumento de matéria fresca em torno de $50 \%$ nas primeiras 24 horas de embebição e $79,3 \%$ no final da fase II (FII), após 144 horas de embebição (Goldman et al., 1987). A FII (fase lag) é caracterizada por uma estabilização do teor de água nas sementes (Bewley e Black, 1985).Neste trabalho houve uma variação de 37,8\%

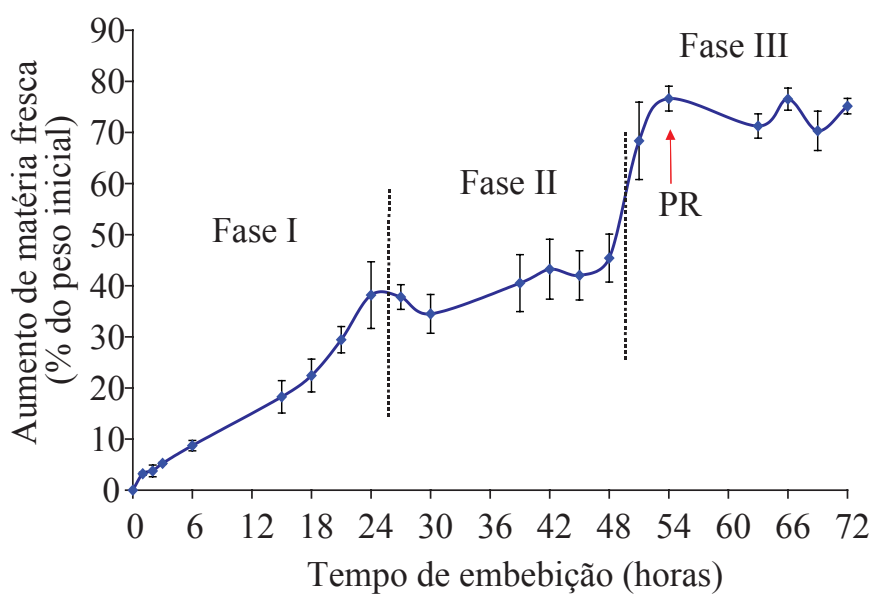

FIGURA 1. Aumento percentual de matéria fresca durante a germinação de sementes de catingueira (Caesalpinia pyramidalis Tull.). $\mathbf{P R}=$ protrusão da raiz. Petrolina, agosto de 2005. 
de água, no início da FII, a 45,4\% no final desta fase, tendo a duração de 27 horas (Figura 1). A FIII é caracterizada pela protrusão da raiz e por uma retomada da absorção de água pelas sementes. No entanto, ao contrário da FI esta fase tem absorção ativa de água sementes (Bewley e Black, 1985) . As sementes de caatingueira apresentaram rápida absorção de água após 48 horas de embebição atingindo 76,6\% de água por ocasião da protrusão da raiz (Figura 1).

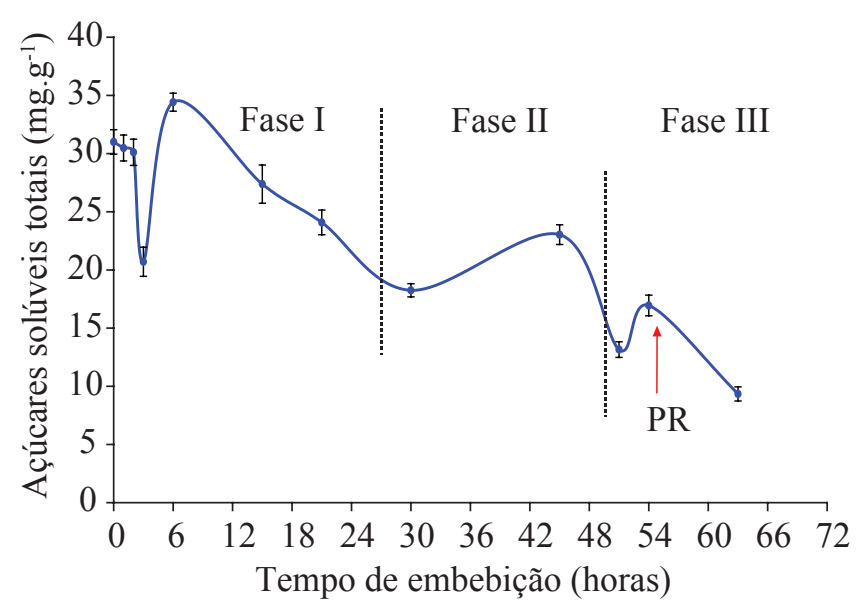

FIGURA 2. Teor de açúcares solúveis totais (mg de glicose. $g^{-1}$ de matéria fresca) durante a germinação de sementes de catingueira (Caesalpinia pyramidalis Tull.). $\mathrm{PR}=$ protrusão da raiz. Petrolina, agosto de 2005.

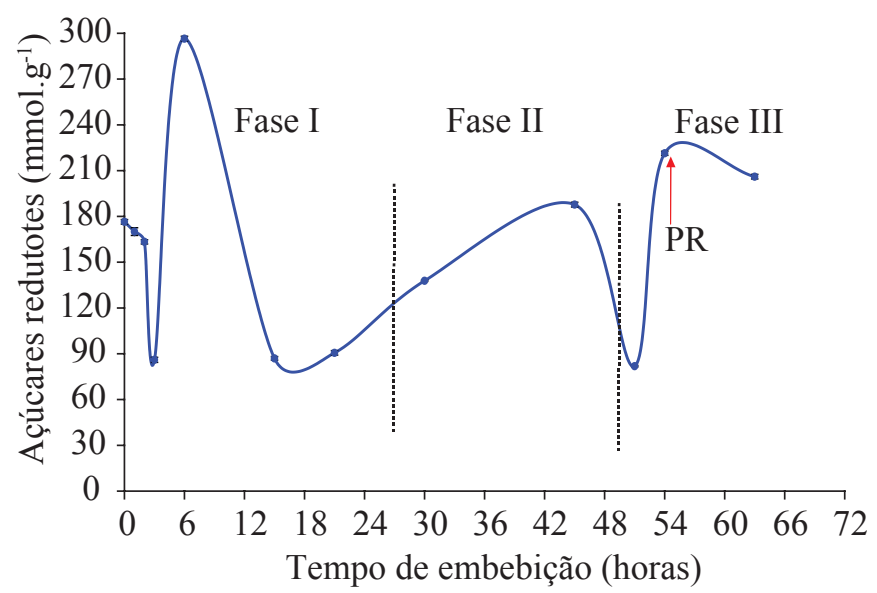

FIGURA 3. Teor de açúcares redutores (mg de glicose. $\mathrm{g}^{-1}$ de matéria fresca) durante a germinação de sementes de catingueira (Caesalpinia pyramidalis Tull.). $\mathbf{P R}=$ protrusão da raiz. Petrolina, agosto de 2005.
Verificou-se que houve um decréscimo nos teores AR, AST e amido das sementes durante as primeiras horas de embebição até 3 horas (Figuras 2, 3 e 4). Os teores de AST, após as primeiras horas de embebição, decrescem gradativamente até o final do período de embebição estudado (Figura 2). Esse resultado é semelhante aos obtidos por Karunagaran e Rao (1991), Pontes et al. (2002) e Seiffert (2002) em que os teores de AST diminuem durante a embebição de sementes de Macrotyloma uniflorum (Fabaceae), Apuleia leiocarpa (Vogel) e de $P$. widgrenii, respectivamente.

Os AR, ao contrário dos AST, ocorrem em altos teores $\left(296,4 \mu \mathrm{mol} . \mathrm{g}^{-1}\right)$ após o início da FI e apresentam uma queda seguida de aumento gradativo de seus teores durante o período de embebição (Figura 3). Por ocasião da protrusão da raiz, estes apresentaram valor aproximado de $221,4 \mu \mathrm{mol} . \mathrm{g}^{-1}$. Sementes de $A$. leiocarpa apresentam aumento dos teores de manose e arabinose (açúcares redutores) no tegumentos e de manose e glicose nos embriões durante a embebição (Pontes et al., 2002). Seiffert (2002) verificou que o teor de AR permanece constante em sementes de $P$. widgrenii durante a embebição das mesmas.

Após as primeiras horas de embebição, o teor de amido sofre um acréscimo atingindo aproximadamente o dobro do valor inicial. Durante a embebição o amido é metabolizado e, ao final do período estudado, atinge valor semelhante ao inicial (Figura 4). O teor de amido nas sementes quiescentes de catingueira é baixo em relação ao teor de AST (4,31 e $31 \mathrm{mg} . \mathrm{g}^{-1}$, respectivamente), sendo, portanto, bastante provável que este não seja o principal carboidrato de

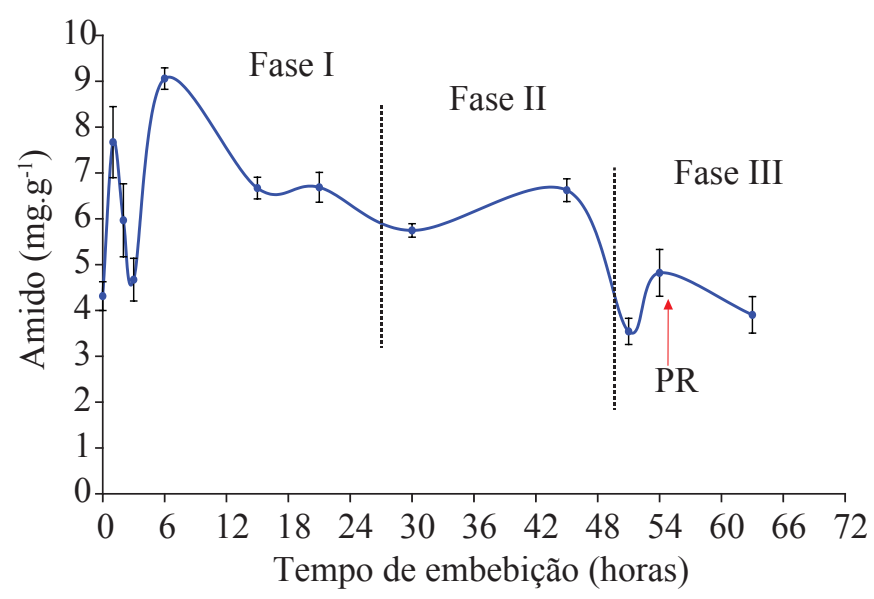

FIGURA 4. Teor de amido (mg de glicose. - $^{-1}$ de matéria fresca) durante a germinação de sementes de catingueira (Caesalpinia pyramidalis Tull.). $\mathrm{PR}=$ protrusão da raiz. Petrolina, agosto de 2005. 
reserva desta espécie. Sementes de $A$. leiocarpa apresentam aumento no teor de amido no cotilédones durante o período de embebição das sementes (Pontes et al., 2002).

Os carboidratos de reserva são hidrolisados a glicose pelas amilases e glucosidases. A glicose então pode ser utilizada prontamente como forma de energia ou ser transportada para o eixo embrionário sob forma de sacarose (Guimarães, 1999).

Os teores de proteínas de reserva têm diferentes comportamentos durante o processo germinativo das sementes. Os teores de albuminas, globulinas e glutelinas apresentaram uma grande variação durante as primeiras horas de embebição (Figuras 5, 7 e 8). Os teores de albuminas, proteínas solúveis em água e geralmente enzimas, diminuem durante a FI e são produzidas novamente durante a FII (Figura 5), sendo que o mesmo comportamento é observado para os teores de globulinas (Figura 6). Os teores de prolaminas e glutelinas decrescem após o início da embebição e se mantém em aproximadamente metade do valores iniciais até o final do período de embebição estudado (Figuras 7 e 8). Pontes et al (2002) e Seiffert (2002) quantificaram apenas as proteínas totais em sementes de $A$. leiocarpa e $P$. widgrenii, respectivamente. Essas autoras verificaram que ocorre aumento no teor de proteínas totais nas sementes durante o processo de embebição que ocorre devido à indução da biossíntese de enzimas hidrolíticas. Neste trabalho a variação inicial dos teores de albumina pode ser explicado pela reidratação e biossíntese de proteínas funcionais (enzimas),

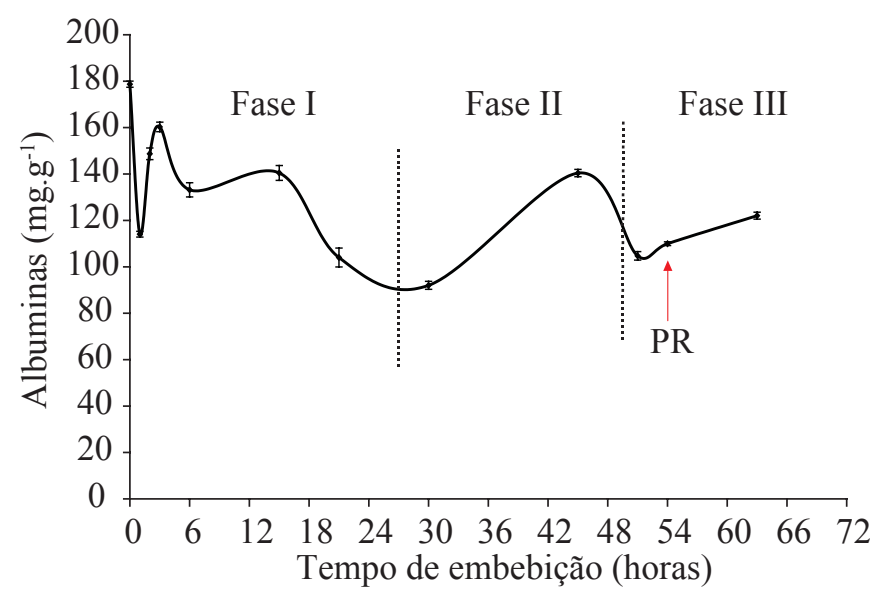

FIGURA 5. Teor de albuminas (mg de caseína. $\mathrm{g}^{-1}$ de matéria fresca) durante a germinação de sementes de catingueira (Caesalpinia pyramidalis Tull.). $\mathbf{P R}=$ protrusão da raiz. Petrolina, abril de 2005. no entanto, ao contrário de sementes de sementes de $A$. leiocarpa e $P$. widgreni as proteínas foram metabolizadas durante o processo de germinação. Suda e Giorgini (2000) verificaram que o teor de albumina de sementes de amendoim bravo (Euphorbia heterophylla L.) se mantém constante até 72 horas após o início da embebição e diminui após isso, o teor de glutelinas decresce após 48 horas e o teor de globulinas tem queda constante durante a embebição das sementes.

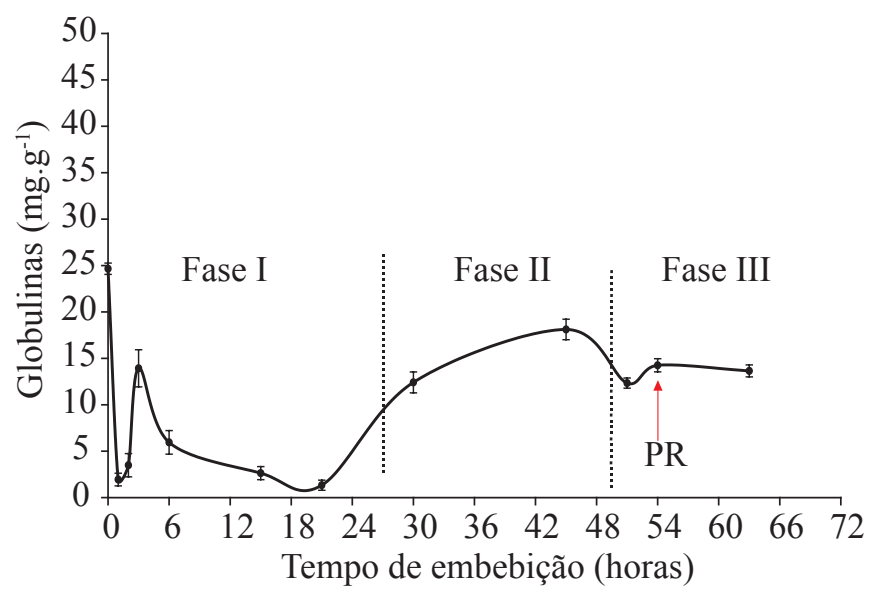

FIGURA 6. Teor de globulinas (mg de caseína. $\mathrm{g}^{-1}$ de matéria fresca) durante a germinação de sementes de catingueira (Caesalpinia pyramidalis Tull.). $\mathbf{P R}=$ protrusão da raiz. Petrolina, abril de 2005.

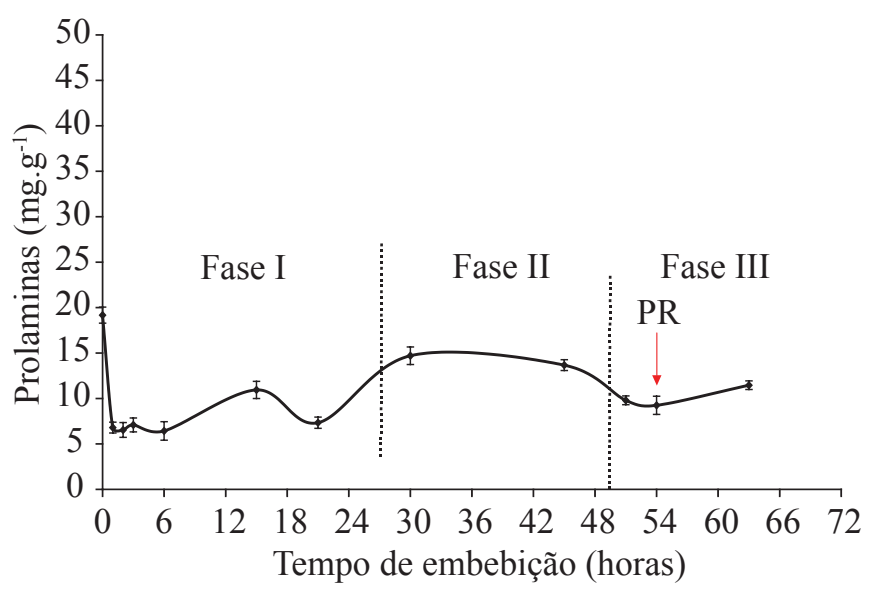

FIGURA 7. Teor de prolaminas (mg de caseína. $\mathrm{g}^{-1}$ de matéria fresca) durante a germinação de sementes de catingueira (Caesalpinia pyramidalis Tull.). $\mathrm{PR}=$ protrusão da raiz. Petrolina, abril de 2005. 


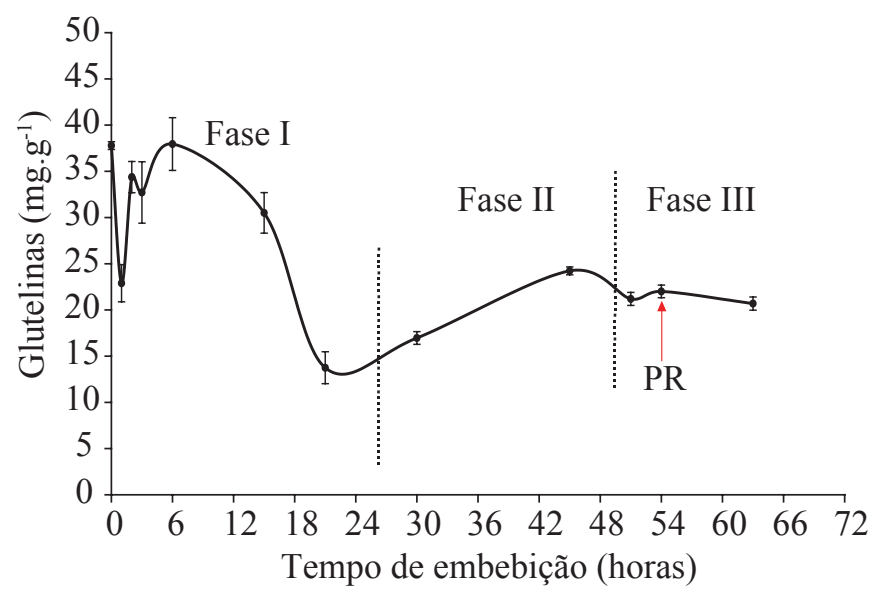

FIGURA 8. Teor de prolaminas (mg de caseína. $\mathrm{g}^{-1}$ de matéria fresca) durante a germinação de sementes de catingueira (Caesalpinia pyramidalis Tull.). $\mathbf{P R}=$ protrusão da raiz. Petrolina, abril de 2005.

\section{CONCLUSÕES}

A germinação das sementes de catingueira (Caesalpinia pyramidalis Tull.) apresenta fases de embebição bem definidas, ocorrendo a protrusão da raiz às 54 horas de embebição. Os teores de açúcares de reserva diminuem durante a embebição e os teores de albuminas, globulinas e glutelinas variam durante as primeiras horas de embebição. Já na fase II ocorre um aumento dos teores de proteínas fracionadas e isso se deve à hidratação das sementes que permitiu a reativação do metabolismo e ativação das enzimas inativas.

\section{REFERÊNCIAS}

ALLEN, S.E.; GRIMSHAW, H.M.; PAKINSON, J.A.; QUARMBY, C. Chemical analysis of ecological materiais. Oxford: Blackwell Scientific, 1977.

ALMEIDA, L.P. Germinação, crescimento inicial e anatomia de plantas jovens de Cryptocaria achersoniama MEZ. sob diferentes níveis de radiação. 2002. 81p. Dissertação (Mestrado em Fisiologia Vegetal)- Universidade Federal de Lavras, Lavras. 2002.

ARAGÃO, C.A.; DANTAS, B.F.; ALVES, E.; CORRÊA, M.R. Sementes de feijão submetidas a ciclos e períodos de hidratação-secagem. Scientia Agrícola. Piracicaba, v.59, n.1, p.87-92, 2003.

BAHIA. Inventário de Plantas Medicinais do Estado da Bahia. Bahia: SEPLANTEC/CADCT, 1979. 25p.
BEWLEY, J.D.; BLACK, M. Seeds: Physiology of development and germination. New York: Plenum Press, 1985, 367p.

BRADFORD, M.M. A rapid and sensitive method for the quantitatification of microgram quantities of protein utilizing the principle of protein-dye binding. Analytical Biochemistry. San Diego, v.72, n.5, p.248-254, 1976.

GOLDMAN, G.H., GOLDMAN, M.H.S.; AGUIAR, J.P.L. Estudo sobre germinação e curva de embebição das sementes: germinação em diferentes temperaturas. Acta Amazonica. Manaus. v.16/17, n.1, p.383-392, 1987.

GUIMARÃES, R.M. Fisiologia de sementes - produção e tecnologia de sementes. Lavras: UFLA/FAEPE, 1999. 129p.

IPEF. Reflorestamento. Disponível em: <http.www.ipef. com.br>, Acesso em: 12 jan. 2000.

KARUNAGARAN, D.; RAO, R. Mode and control of starch mobilization during germination of seeds of horse gram. Plant Science, Limerick, v.73, n.2, p.155-159, 1991.

LIMA, J.L.S. Plantas forrageiras das caatingas: usos e potencialidades. Petrolina: Embrapa Semi-Arido/ PNE/ RBG-KEW, 1996. 44p.

MILLER, G.L. Use dinitrosalicylis acid reagent for determination of reducing sugars. Analytical Chemistry, Washington, v.31, n.2, p.426-428, 1959.

MORRIS, D.L. Quantitative determination of carbohydrates with Drywood's anthrone reagent. Science,Washigton, v.107, n.3, p. 254-255, 1948.

NASSIF, S.M.L.; VIEIRA, I.G.; GELSON, D.F. Fatores externos (ambientais) que influenciam na germinação de sementes. Disponível em: <http://www.ipef.br/tecsementes/ germinacao.asp>, Acesso em: 05 mar. 2005.

NISHIZAWA, T.; TSUCHIYA, A.; PINTO, M.M.V. Characteristics and utilization of tree species in the semi-arid woodland of north-east Brazil In: Nishizawa, T.; Uitto, J.I. The fragile tropics of Latin America: sustainable management of changing environments. Disponível em: <http://www.unu.edu/unupress/ unupbooks/80877e/80877E00.htm\#Contents $>$, Acesso em: 05 mar. 2005.

OLIVEIRA, O.F. Caatinga. Mossoró: ESAM, 1976. 86p.

PFEISTER, J.A. e MALECHEK, J.C. Dietary selection by goats and sheep in a deciduous woodland of Northeastern Brazil. Journal of Range Management, Baltimore, v.39, n.1, p.24-28. 1986.

PONTES, C.A.; BORGES, E.E.L.; BORGES, R.C.G.; 
SOARES, C.P.B. Mobilização de reserva em sementes de Apuleia leiocarpa (Vogel) J.F. Macbr. (garapa) durante a embebição. Revista Árvore, Viçosa, v.26, n.5, p.593-601, 2002.

SAMPAIO, E.; RODAL, M.J. Biodiversidade da caatinga, Disponível em: <http//www.biodiversitas.org/caatinga $>$, Acesso em: 12 jan. 2000.

SEIFFERT, M. Alguns aspectos fisiológicos e bioquímicos da germinação de sementes e anatomia foliar de Protium widgrenii Engler. 2002. 81p. Dissertação(Mestrado em Fisiologia Vegetal)- Universidade Federal de Lavras, Lavras. 2002.

SUDA, C.N.K.; GIORGINI, J.F. Seed reserve composition and mobilization during germination and initial seedling development of Euphorbia heterophylla. Revista Brasileira de Fisiologia Vegetal, Londrina, v.12, n.3, p.226-245, 2000.

YEMM, E.W.; WILLIS, A.J. The estimation of carbohydrates in plants extracts by anthrone. Biochemical Journal, Colchester, v.57, n. 4, p.508-514, 1954. 